\title{
Lemierre's syndrome: cavitary lung disease caused by uncommon bacteria
}

\author{
Parmjyot Singh, ${ }^{1}$ Ajay Adial, ${ }^{1}$ Jack Mann, ${ }^{1}$ Asma Iftikhar ${ }^{1,2}$
}

${ }^{1}$ Pulmonary/Critical Care Medicine, NewYork-Presbyterian Queens, Flushing, New York, USA

${ }^{2}$ Northwell Health System, Manhasset, New York, USA

\section{Correspondence to} Dr Asma Iftikhar, doctorasmi@gmail.com

Accepted 4 April 2018
Check for updates

To cite: Singh $P$, Adial $A$, Mann J, et al. BMJ Case Rep Published Online First: [please include Day Month Year]. doi:10.1136/bcr-2018224713

\section{DESCRIPTION}

A 32-year-old Asian man with a history of gastritis presented to the emergency room with abdominal pain, fever, cough and dyspnoea, one episode of haemoptysis. He also reported a sore throat 3 days ago. The patient was a sushi chef and an active smoker. Early lab work was remarkable for leucocytosis of $21 \times 10^{9} / \mathrm{L}$, lactic acidosis of $3 \mathrm{mmol} / \mathrm{L}$, bandaemia of $19 \%$ with a procalcitonin of $>100$ and platelets of $74 \times 10^{9} / \mathrm{L}$. CT of the lungs was performed without contrast and was significant for multiple cavity lesions throughout the lungs (figures 1 and 2). The patient was intubated due to respiratory failure. He was empirically started on vancomycin, cefepime and azithromycin. A right internal jugular central line was attempted for triple lumen catheter placement but the vessel was not compressible. A CT scan of the neck revealed a right internal jugular vein $9 \mathrm{~mm}$ thrombosis (figure 3). Blood culture grew Fusobacterium necrophorum. The antibiotics were switched to ampicillin-sulbactam. Bronchoscopy and bronchoalveolar lavage returned negative for fungal infection, Legionella, Pneumocystis jiroveci and acid fast bacilli as well as negative for HIV, urine Streptococcus and Legionella test and the nasal influenza. A transthoracic echo did not reveal vegetation to suggest endocarditis. The patient did receive short course of anticoagulation, but as repeat CT neck was not showing any further extension of clot, anticoagulation was discontinued. Eventually, the patient improved and discharged home on amoxicillin-clavulanic acid for 2 months. Lemierre's syndrome is defined as suppurative thrombophlebitis of the internal jugular vein often preceding an upper respiratory infection such as pharyngitis. The bacterial culprit is primarily F. necrophorum, affecting young healthy individuals. ${ }^{1}$ The causative

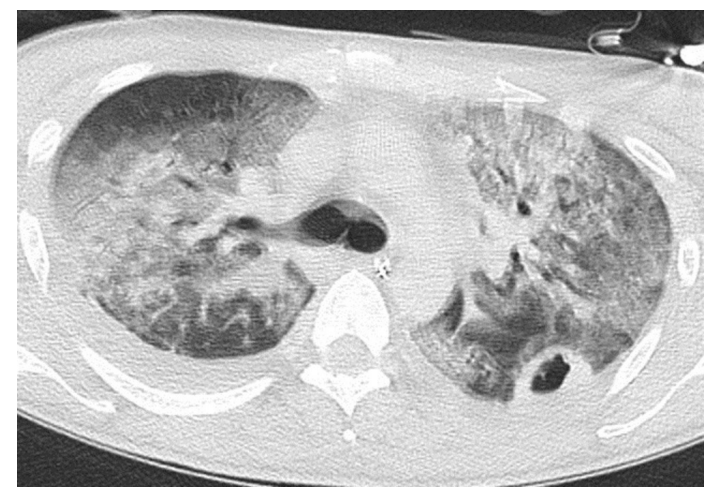

Figure 1 (Axial View) CT of the Chest revealed multiple cavity lesions throughout the lungs.

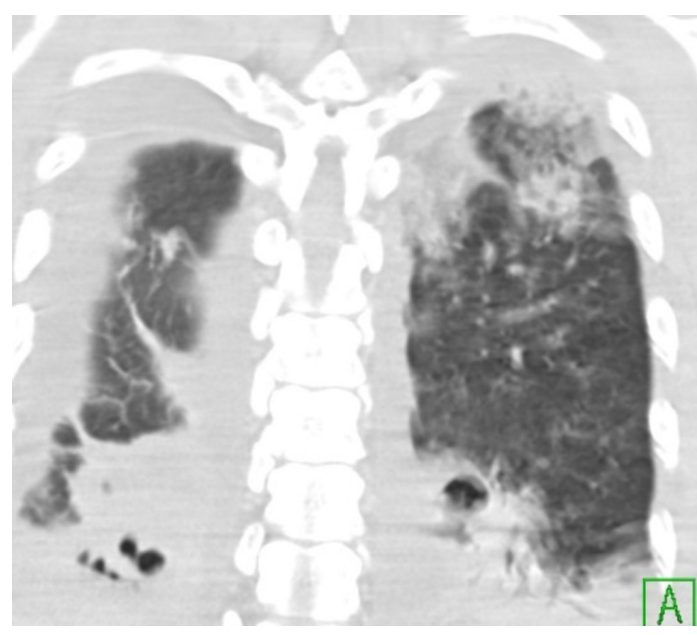

Figure 2 (Coronal View) CT of the Chest revealed multiple cavity lesions throughout the lungs.

bacteria can penetrate, either through the lymphatic system or along the fascial planes, into the adjacent blood vessels causing thrombosis and subsequent thrombophlebitis of the internal jugular vein, often forming parapharyngeal inflammation and a peritonsillar abscess along the way. The presence of haemagglutinin promotes the fulminant nature of the disease by augmenting platelet aggregation and septic thrombus formation. ${ }^{2}$ The propagation of the septic emboli throughout the body causes a cascade

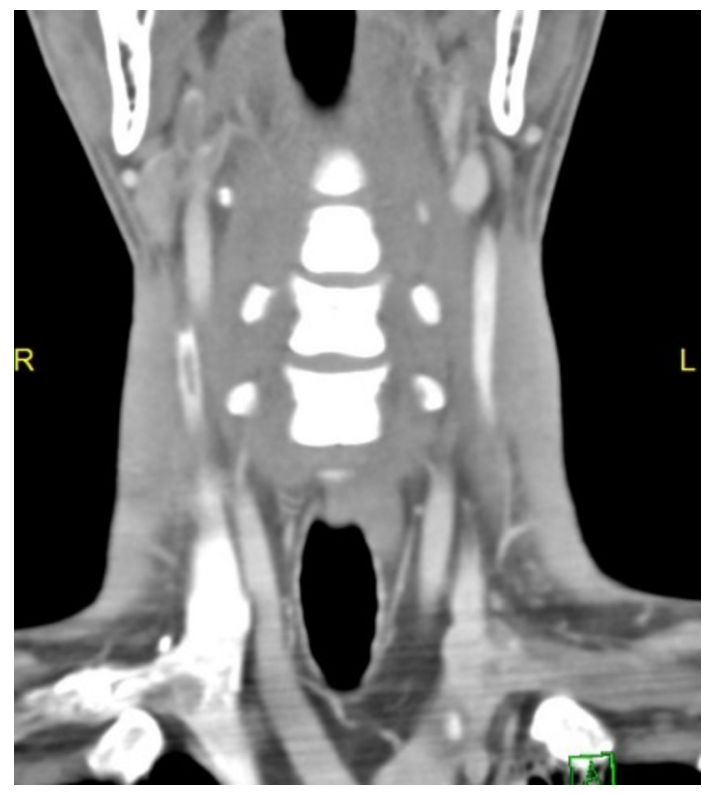

Figure 3 A CT scan of the neck revealed a right internal jugular vein $9 \mathrm{~mm}$ thrombosis. 
of disastrous effects, most commonly lodging into the lungs and creating cavitary lesions. Considering the overall severity of the septicemic illness, acute respiratory distress syndrome occurs in a relatively small proportion of cases. The location of the primary infection is an important prognostic factor: infection in the oropharyngeal location (compared with other sites) was associated with a higher risk of longer intensive care unit stays due to complications such as respiratory problems. Studies from the modern era have reported mortality rates from $0 \%$ to $18 \%$. Disseminated intravascular coagulation has been reported in 3\%-9\% of cases. Mild elevation of blood urea nitrogen and creatinine with haematuria is not uncommon but acute renal failure is rare and the possible aetiology includes either septic emboli to kidneys or acute septic tubular necrosis. Meningitis may also complicate up to $3 \%$ of cases. Blood cultures, chest

\section{Learning points}

Lemierre's syndrome is most commonly caused by Fusobacterium necrophorum.

The propagation of the septic emboli throughout the body causes a cascade of disastrous effects, most commonly lodging into the lungs and creating cavitary lesions. Prolonged antibiotic therapy is the cornerstone of treatment, occasionally combined with anticoagulation.
X-ray and CT chest should be enough to provide a diagnosis. Antibiotics should be started as early as possible. The role of anticoagulation is still controversial. ${ }^{3}$

Contributors AA was involved in the substantial contribution to the conception of the work; drafted the work; was involved in the approval of the version published; and agrees to be accountable for all aspects of the work. JM was involved in the substantial contribution to the acquisition of data and design of the work. PS was involved in the substantial contribution to the conception and design of the work. Al was involved in the substantial contribution to the conception of the work. JM, PS and Al revised the work critically for important intellectual content; were involved in the final approval of the version published; and agree to be accountable for all aspects of the work.

Funding The authors have not declared a specific grant for this research from any funding agency in the public, commercial or not-for-profit sectors.

Competing interests None declared.

Patient consent Obtained.

Provenance and peer review Not commissioned; externally peer reviewed.

(c) BMJ Publishing Group Ltd (unless otherwise stated in the text of the article) 2018. All rights reserved. No commercial use is permitted unless otherwise expressly granted.

\section{REFERENCES}

1 Rae J, Misselbrook K. Lemierre's syndrome - a rare cause of disseminated sepsis requiring multi-organ support. J Intensive Care Soc 2017;18:329-33.

2 Alperstein A, Fertig RM, Feldman M, et al. Septic thrombophlebitis of the internal jugular vein, a case of Lemierre's syndrome. Intractable Rare Dis Res 2017;6:137-40.

3 Golpe R, Marín B, Alonso M, et al. Lemierre's syndrome (necrobacillosis). Postgrad Med J 1999:75:141-4

Copyright 2018 BMJ Publishing Group. All rights reserved. For permission to reuse any of this content visit http://group.bmj.com/group/rights-licensing/permissions.

BMJ Case Report Fellows may re-use this article for personal use and teaching without any further permission.

Become a Fellow of BMJ Case Reports today and you can:

- Submit as many cases as you like

- Enjoy fast sympathetic peer review and rapid publication of accepted articles

- Access all the published articles

Re-use any of the published material for personal use and teaching without further permission

For information on Institutional Fellowships contact consortiasales@bmjgroup.com

Visit casereports.bmj.com for more articles like this and to become a Fellow 